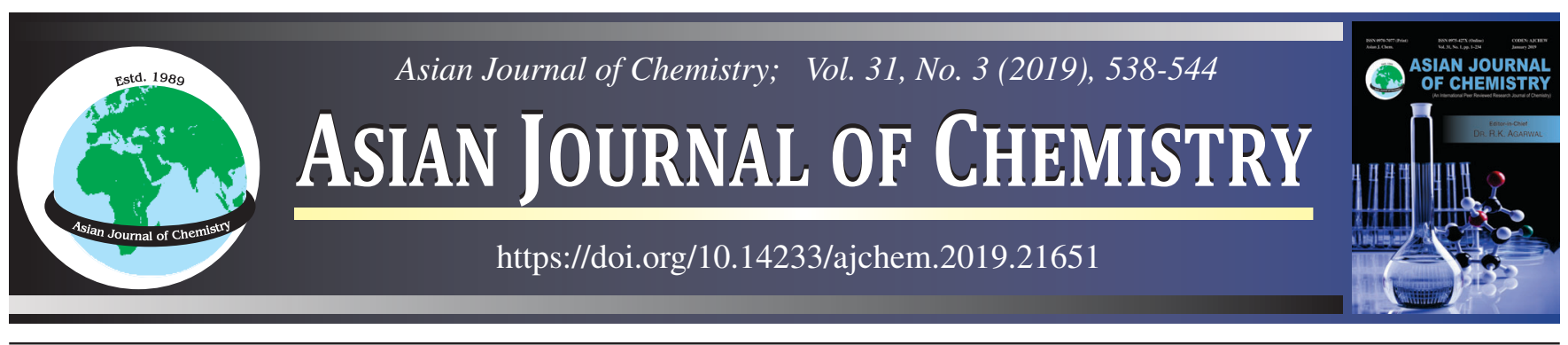

\title{
Study of Intermolecular Interactions between 2-Chloroaniline Isomeric Butanol Complexes in Gas Phase by Using DFT, NBO, QTAIM and RDG Analysis
}

\section{M.Chandra Sekhar ${ }^{1, *}$, Dereje Wakgari ${ }^{2}$, Dunkana Negussa Kenie ${ }^{3}$ and K. Chandrasekhar Reddy ${ }^{4}$}

${ }^{1}$ Department of Physics, Vignan Institute of Technology and Science, Pochampally Mandal-508284, India

${ }^{2}$ Department of Physics, Wollega University, Nekemte, Ethiopia

${ }^{3}$ Department of Chemistry, Wollega University, Nekemte, Ethiopia

${ }^{4}$ Department of Physics, Sri Sai Baba National Degree College, Anantapur-515001, India

*Corresponding author: E-mail: sekharchandra6@gmail.com

Received: 13 August 2018; Accepted: 5 October 2018;

\begin{abstract}
Density functional theoretical (DFT) studies on intermolecular hydrogen bond interactions between self and cross-associated molecular complexes of 2-chloroaniline and isomeric butanols (e.g., 2-methyl-2-propanol, 2-methyl-1-propanol, 2-butanol and1-butanol) have been analyzed in gas phase. Thirteen 2-chloroaniline isomeric butanol complexes are analyzed at B3LYP/6-311++G(d,p) level regarding their geometries, bond characteristics and interaction energies. The second-order perturbation stabilization energy has been calculated by natural bond orbitals analysis. Barder's quantum theory of atoms in molecules are employed to elucidate electron density ( $\rho$ ) as well as its Laplacian $\left(\nabla^{2} \rho\right)$ of the complexes. Further to evaluate the strong and weak interactions between the selected molecular complexes noncovalent interactions plots we used the reduced gradient method.
\end{abstract}

Keywords: 2-Chloroaniline, Isomeric butanols, Hydrogen bonding, Natural bond orbital, Non-covalent interactions, DFT.

\section{INTRODUCTION}

In recent years, large number of theoretical studies has been devoted to explanation of intermolecular hydrogen bonding interactions between the molecular systems [1-6]. Hydrogen bond due to its stability, directionality and dynamics plays a prominent role salvation process $[7,8]$, chemical and biological process, supramolecular chemistry $[9,10]$. The understanding of hydrogen bonding interactions in the molecular systems is useful to analyze the structure of various biomolecules, biochemical process and molecular recognition.

Intermolecular interactions play an imperative role in studying the structures and physico-chemical properties of the organic molecular systems. So various quantum mechanical methods are essential to calculate structural features, energies and electronic properties of hydrogen bonded systems. Based on the quantum mechanical study of interaction various molecular devices, nanomterials and novel functional molecules can be developed. Generally, present selected molecular systems for investigation having a variety of commercial applications.
2-Chloroaniline has vast industrial importance, which include in oil solvents, fungicides and an intervening agent in the synthesis of azo dyes, agricultural chemicals and prescription drugs and also used in petroleum solvents. Isomeric butanols are widely used in aviation, textile, food, medicine, automotive surface coatings and petroleum industries.

In continuation of our previous report [11] we investigated the influence of position of $-\mathrm{CH}_{3}$ groups in butanols which forms hydrogen bonding interactions with 2-chloroaniline. To analyze $\mathrm{H}$-bonding microscopically the geometrical parameters $\left(\Delta \mathrm{R}_{\mathrm{X} . . \mathrm{H}}, \mathrm{R}_{\mathrm{H} \ldots \mathrm{Y}}, \Delta \mathrm{R}_{\mathrm{H} \ldots \mathrm{Y}}\right)$ interaction energies $\left(\Delta \mathrm{E}_{\mathrm{cp}}\right)$, second-order perturbation stabilization energies $[\mathrm{E}(2)]$ and charge densities $\left(\rho, \nabla^{2} \rho\right)$ are studied by using DFT in gas phase.

\section{COMPUTATIONAL METHODS}

The main objective of DFT simulations is to analyze the intermolecular interaction between 2-chloroaniline and isomeric butanol complexes in gas phase. The geometrical parameters, interactions energies and second-order perturbation stabilization energies were carried by using method and with

This is an open access journal, and articles are distributed under the terms of the Creative Commons Attribution-NonCommercial-ShareAlike 4.0 (CC BY-NC-SA 4.0) International License which allows readers to freely read, download, copy, distribute, print, search, or link to the full texts of its articles and to use them for any other lawful non-commercial purpose as long as the original source is duly acknowledged. 
basis set B3LYP/6-311++G(d,p). All these simulations in gas phase were carried out using Gaussian 03. The Barder's Quantum theory of atoms in molecules (QTAIM) analysis were carried out by using Multiwfn program [12] in order to calculate the charge density, Laplacian charge density, total electron energy density at bonding critical point (BCP) to analyze the nature of H-bonding. Furthermore, reduced density gradient (RDG) method was used to analyze the H-bonding between 2-chloroaniline and isomeric butanols.

\section{RESULTS AND DISCUSSION}

Geometrical optimization: Thirteen possible self- and cross-associated H-bonded complexes between 2-chloroaniline and isomeric butanols systems are shown in Fig. 1. The optimized structural parameters of self- and cross-associated complexes of 2-chloroaniline and butanols have been calculated at B3LYP/6-311++G(d,p) level of theory and are shown in Table-1.

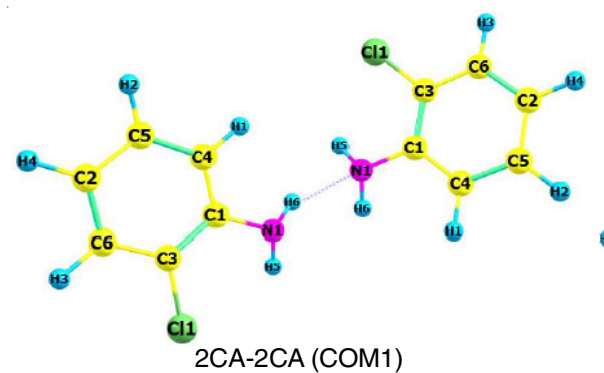

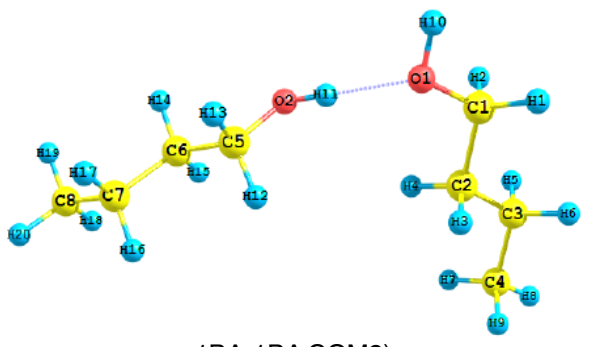

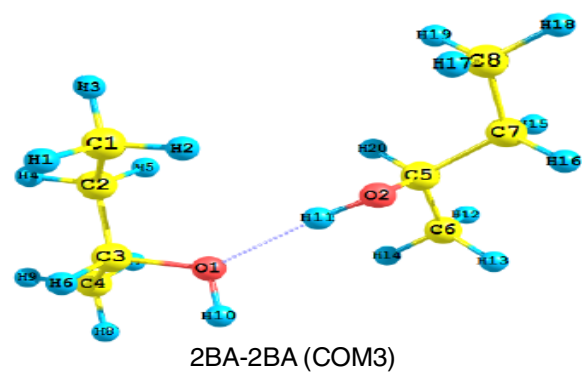

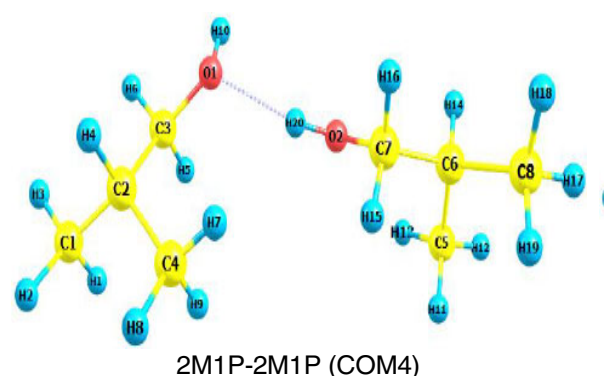

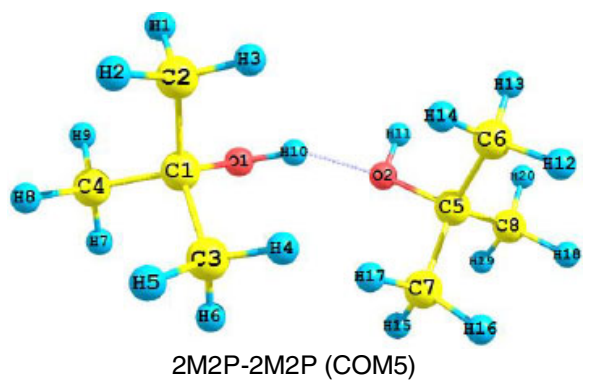

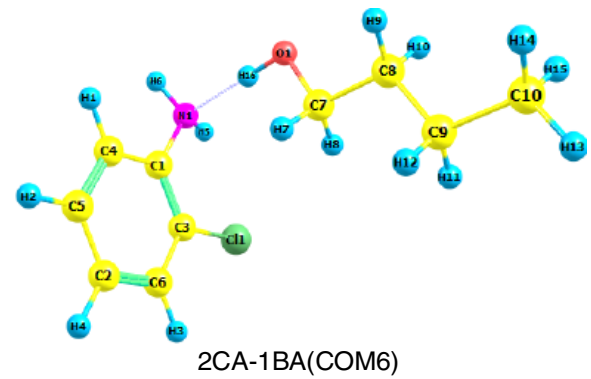

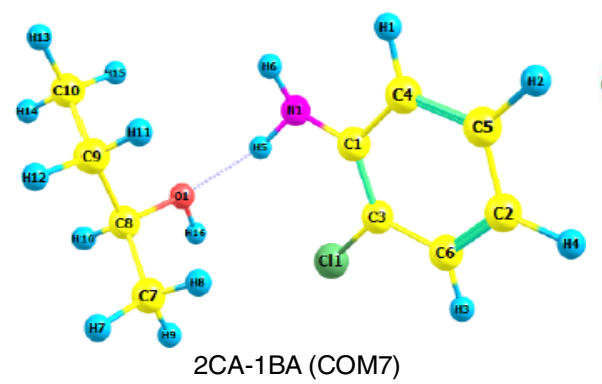

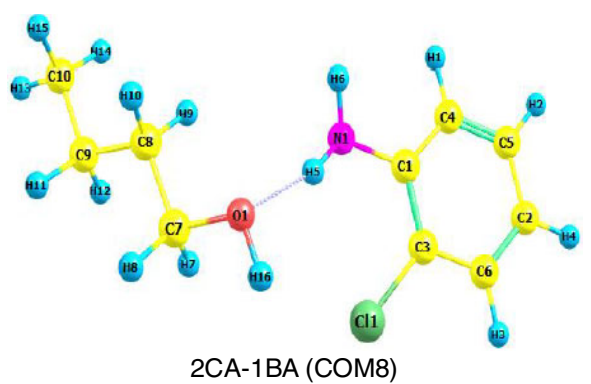

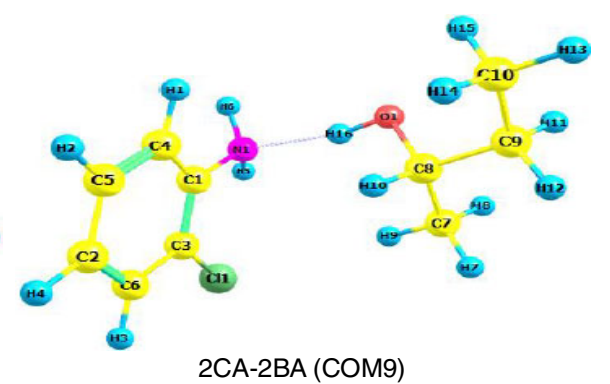

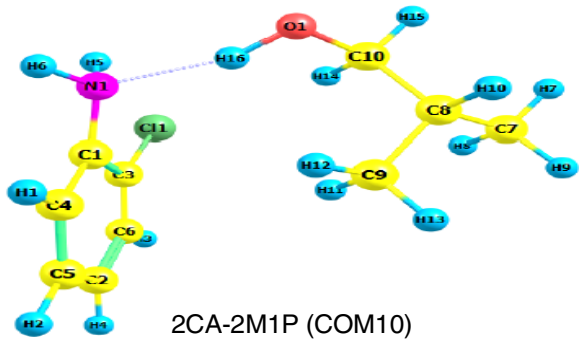

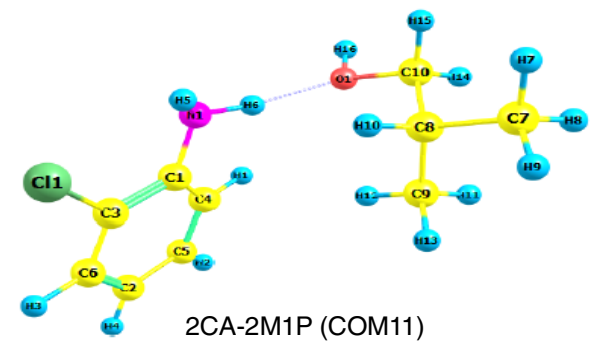<smiles>CC(C)=O</smiles>

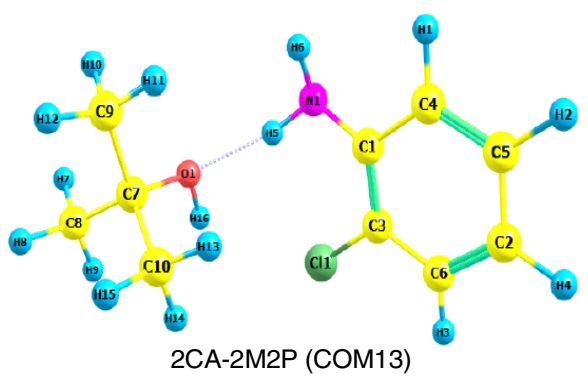

Fig. 1. Optimized structural parameters of self- and cross-associated complexes of 2-chloroaniline and butanols 
TABLE-1

DISTANCES $(\AA)$ AND ANGLES $\left({ }^{\circ}\right)$ OF THE HYDROGEN BONDS FOR ALL HYDROGEN BOND ASSOCIATIONS AT B3LYP/6-311++G(d, p)

\begin{tabular}{|c|c|c|c|c|c|c|c|}
\hline Complexes & $\mathrm{X}-\mathrm{H} \cdots \mathrm{Y}$ & $\mathrm{R}(\mathrm{X}-\mathrm{H})$ & $\Delta \mathrm{R}(\mathrm{X}-\mathrm{H})$ & $\mathrm{R}(\mathrm{H} \cdots \mathrm{Y})$ & $\Delta \mathrm{R}(\mathrm{H} \cdots \mathrm{Y})$ & $\mathrm{R}(\mathrm{X} \cdots \mathrm{Y})$ & $\angle \mathrm{XHY}$ \\
\hline COM1 & $\mathrm{N} 2-\mathrm{H} 11 \cdots \mathrm{N} 1$ & 1.01416 & 0.00611 & 2.26065 & 0.48935 & 3.24571 & 168.45 \\
\hline COM2 & $\mathrm{O} 2-\mathrm{H} 20 \cdots \mathrm{O} 1$ & 0.97236 & 0.0107 & 2.02296 & 0.69704 & 2.98531 & 175.69 \\
\hline COM3 & $\mathrm{O} 2-\mathrm{H} 20 \cdots \mathrm{O} 1$ & 0.97243 & 0.01021 & 2.04414 & 0.67586 & 2.99629 & 174.56 \\
\hline COM4 & $\mathrm{O} 2-\mathrm{H} 20 \cdots \mathrm{O} 1$ & 0.97065 & 0.00729 & 2.11378 & 0.63622 & 3.03285 & 167.38 \\
\hline COM5 & $\mathrm{O} 1-\mathrm{H} 1 \cdots \mathrm{O} 2$ & 0.97268 & 0.00932 & 2.06960 & 0.65040 & 3.01333 & 168.23 \\
\hline COM6 & $\mathrm{O} 1-\mathrm{H} 16 \cdots \mathrm{N} 1$ & 0.97033 & 0.00867 & 1.98212 & 0.76788 & 3.01540 & 166.94 \\
\hline COM7 & N1-H5 ‥O1 & 1.01512 & 0.00708 & 2.06799 & 0.65201 & 3.05156 & 162.53 \\
\hline COM8 & 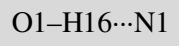 & 0.97031 & 0.00809 & 1.96177 & 0.78823 & 3.02311 & 163.02 \\
\hline COM9 & N1-H5 $\cdots \mathrm{O} 1$ & 1.01457 & 0.00653 & 2.09109 & 0.62891 & 3.09317 & 169.03 \\
\hline COM10 & $\mathrm{O} 1-\mathrm{H} 16 \cdots \mathrm{N} 1$ & 0.96812 & 0.00677 & 1.94912 & 0.80088 & 3.02119 & 161.97 \\
\hline COM11 & 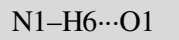 & 1.01384 & 0.00580 & 2.04350 & 0.67650 & 3.05062 & 171.87 \\
\hline COM12 & $\mathrm{O} 1-\mathrm{H} 16 \cdots \mathrm{N} 1$ & 0.97010 & 0.00875 & 1.93304 & 0.81696 & 2.87776 & 163.92 \\
\hline COM13 & $\mathrm{N} 1-\mathrm{H} 5 \cdots \mathrm{O} 1$ & 1.01487 & 0.00683 & 2.09245 & 0.62755 & 3.09245 & 168.23 \\
\hline
\end{tabular}

As shown in the Fig. 1 the complexes have intermolecular hydrogen bonds. The H-bonds are formed between hydroxyl group $(-\mathrm{OH})$ of isomeric butanols and $-\mathrm{NH}_{2}$ group of 2-chloroaniline. This study reveals that $\mathrm{O}-\mathrm{H} \cdots \mathrm{N}$ and $\mathrm{N}-\mathrm{H} \cdots \mathrm{O}$ hydrogen bonds are formed between amine group of 2-chloroaniline and hydroxy group of isomeric butanols.

During the hydrogen bond formation the stretching of bond length of the proton donor $\Delta \mathrm{R}_{\mathrm{X}-\mathrm{H}}$ from its corresponding monomer indicates the strength of the hydrogen bond [13]. Table-1 shows the complex COM12 have shortest H-bond length $1.93304 \AA(\mathrm{O} 1-\mathrm{H} 16 \cdots \mathrm{N} 1)$ between the $\mathrm{O}-\mathrm{H}$ proton donor of 2-methyl-2-propanol (2M2P) and nitrogen atom of 2-chloroaniline (2CA). The largest change in bond length $\Delta \mathrm{R}_{\mathrm{O} 1-}$ H16 is $0.00932 \AA$. This shows that COM12 $(2 \mathrm{CA}+2 \mathrm{M} 2 \mathrm{P})$ is the strongest and stable $\mathrm{H}$-bond among thirteen complexes. The second shortest and strong H-bond is observed in COM10 with a bond length of $1.94912 \AA$ and the second largest change in the bond length of proton donor $\Delta \mathrm{R}_{\mathrm{O} 1-\mathrm{H} 16}$ is $0.00875 \AA$ in 2 chloroaniline and 2-methyl-1-propanol complex. The largest $\Delta \mathrm{R}_{\mathrm{O} 1 \mathrm{H} 16}$ in COM10 shows the second strongest hydrogen bonding in 2-chloroaniline and 2-methyl-1-propanol complex. Similarly the H-bond present in 2-chloroaniline-2-butanol association of COM8 is third strong hydrogen bond with a bond length of $1.96177 \AA$ and $\Delta \mathrm{R}_{\mathrm{X}-\mathrm{H}}$ value is $0.00867 \AA$. In addition, other $\mathrm{H}$-bond involving between 2-chloroanilineisomeric butanol complexes should be weaker than above three H- bonds [14].

Further a parameter $\Delta R_{H \cdots Y}[15]$, is defined as $\Delta R_{H \cdots Y}=$ $\mathrm{R}_{\mathrm{H}_{\mathrm{vwr}}}+\mathrm{R}_{\mathrm{Y}_{\mathrm{vwr}}}-\mathrm{R}_{\mathrm{H} \ldots \mathrm{Y}}$, where $\mathrm{R}_{\mathrm{H}_{\mathrm{vwr}}}$ and $\mathrm{R}_{\mathrm{Y}_{\mathrm{vwr}}}$ are the vander Waals radii of hydrogen and electronegative atoms [16]. $\Delta \mathrm{R}_{\mathrm{H} \ldots \mathrm{Y}}$ is the hydrogen bond distance. The value of $\Delta R_{H \cdots Y}$ is used to scrutinize the hydrogen bond strength of the complexes. The largest value of $\Delta \mathrm{R}_{\mathrm{H} \cdots \mathrm{Y}}$ is 0.81696 for COM12 with $\mathrm{OH} \cdots \mathrm{N}$ interaction is the strongest hydrogen bond. Based on the resulted values of $\Delta \mathrm{R}_{\mathrm{X}-\mathrm{H}}$ and $\Delta \mathrm{R}_{\mathrm{H} \cdots \mathrm{Y}}$ the strength of the hydrogen bond are in the order is

\section{COM12 $>$ COM10 $>$ COM8 $>$ COM6 $>\mathrm{COM2}>$ COM11 $>$ COM3 $>$ COM7 $>$ COM5 $>$ COM9 $>$ COM13 $>$ COM4 $>$ COM1 $>$}

which shows the 2-chloroaniline + 2-methyl-2-propanol dimer (COM12) shows strong interaction by hydrogen bonding between nitrogen atom of 2-chloroaniline and hydrogen atom of 2-methyl-2-propanol. This show the geometrical results are good in agreement with the experimental results [11].

Interaction energy analysis: In order to calculate the interaction energy of the H-bond, the sum of the energies of the two monomers was subtracted from the energy of the molecular complex. The energy difference gives the energy contribution due to the specific hydrogen bond. However, in the energy determination of the $\mathrm{X}$... Y heterodimer, all the orbitals of both $\mathrm{X}$ and $\mathrm{Y}$ are available to the dimer. As a consequence the basis set of each monomer is extended by the presence of the other, which results in a mathematical lowering of the monomer energies. This is referred to as the basis set superposition error (BSSE) [17]. The counterpoisecorrected interaction energies, $\Delta \mathrm{E}^{\mathrm{cp}}$ for thirteen complexes were computed at B3LYP/6-311++G(d,p) are presented in Table-2.

TABLE-2

INTERACTION ENERGY CORRECTED WITH BSSE $\left(\Delta \mathrm{E}_{\mathrm{c}}\right.$, $\mathrm{kJ} \mathrm{mol}^{-1}$ )FOR ALL DIMERS AT B3LYP/6-311++G (d,p) LEVEL

\begin{tabular}{|c|c|c|c|c|}
\hline Complexes & $\mathrm{X}-\mathrm{H} \cdots \mathrm{Y}$ & $\Delta \mathrm{E}$ & BSSE & $\Delta \mathrm{E}_{\mathrm{CP}}$ \\
\hline COM1 & N2-H1 $1 \cdots \mathrm{N} 1$ & -13.59473 & 1.10 & -12.4947 \\
\hline COM2 & $\mathrm{O} 2-\mathrm{H} 20 \cdots \mathrm{O} 1$ & -21.8671 & 1.94 & -19.9271 \\
\hline COM3 & $\mathrm{O} 2-\mathrm{H} 20 \cdots \mathrm{O} 1$ & -20.4807 & 0.78 & -19.7004 \\
\hline COM4 & $\mathrm{O} 2-\mathrm{H} 20 \cdots \mathrm{O} 1$ & -20.4591 & 0.75 & -18.3959 \\
\hline COM5 & $\mathrm{O} 1-\mathrm{H} 1 \cdots \mathrm{O} 2$ & -19.1459 & 0.75 & -18.3959 \\
\hline COM6 & $\mathrm{O} 1-\mathrm{H} 16 \cdots \mathrm{N} 1$ & -21.8849 & 0.91 & -22.2703 \\
\hline COM7 & $\mathrm{N} 1-\mathrm{H} 5 \cdots \mathrm{O} 1$ & -16.7528 & 1.06 & -15.7102 \\
\hline COM8 & $\mathrm{O} 1-\mathrm{H} 16 \cdots \mathrm{N} 1$ & -24.4359 & 1.01 & -20.5939 \\
\hline COM9 & N1-H5 -.O1 & -14.7713 & 0.96 & -15.2457 \\
\hline COM10 & $\mathrm{O} 1-\mathrm{H} 16 \cdots \mathrm{N} 1$ & -26.8241 & 2.41 & -18.2132 \\
\hline COM11 & N1-H6 $\cdots \mathrm{O} 1$ & -18.7668 & 0.93 & -17.8368 \\
\hline COM12 & $\mathrm{O} 1-\mathrm{H} 16 \cdots \mathrm{N} 1$ & -27.3737 & 2.39 & -24.9837 \\
\hline COM13 & N1-H5 -.O 1 & -15.0888 & 1.05 & -14.0388 \\
\hline
\end{tabular}

Table-2 shows that for 2-chloroaniline and 2-methyl-2propanol 1:1 complex (COM12 - COM13) the interaction energies are -24.9837 and $-10.146 \mathrm{KJ} \mathrm{mol}^{-1}$, respectively. In the case of 2-chloroaniline and 2-methyl-1-propanol 1:1 complex (COM10 - COM11) the interaction energies are in the range of -18.2132 to $-17.8368 \mathrm{KJ} \mathrm{mol}^{-1}$. The COM12 of 2-chloroaniline and 2-methyl-2-propanol 1:1 association has larger interaction energy $\left(-24.9837 \mathrm{KJ} \mathrm{mol}^{-1}\right)$ compared 
to 2-chloroaniline and 2-methyl-1-propanol (COM10) due to presence of the shorter $\mathrm{O}-\mathrm{H} \cdots \mathrm{N}$ hydrogen bond (1.98905 $\AA$ ). This is due to hydrogen atom of hydroxy group in 2-methyl2-propanol is a little more acidic due to the $+\mathrm{E}$ effect of three $-\mathrm{CH}_{3}$ group on the $\alpha$-carbon atom to a greater hydrogen bond than that of 2-methyl-1-propanol.

The calculated interaction energies for the complexes COM8 - COM9 of 2-chloroaniline and 2-butanol that involved $\mathrm{N}-\mathrm{H} \cdots \mathrm{O}$ and $\mathrm{O}-\mathrm{H} \cdots \mathrm{N}$ interactions are -20.5939 and $-15.2457 \mathrm{KJ} \mathrm{mol}^{-1}$. Finally, in the case of 2-chloroaniline and 1-butanol 1:1 complex (COM6 - COM7) the interaction energies are in the range of -22.2703 to $-15.7102 \mathrm{KJ} \mathrm{mol}^{-1}$. These results shows the strong H-bond is observed in 2-chloroaniline + 2-butanol mixture compared to 2-chloroaniline + 1butanol mixture. This is because of presence of two methyl groups $\left(-\mathrm{CH}_{3}\right)$ increases electron density at oxygen atom of hydroxy group to a greater extent compared to that of 1-butanol. This is in good agreement with the results of geometrical optimization.

Quantum theory of atom in molecular (QTAIM) analysis: QTAIM analysis on 2-chloroaniline and isomeric butanol 1:1 complexes for investigations of intermolecular hydrogen bond interactions was studied at B3LYP/6-311++G(d,p) level of theory. In this QTAIM analysis a chemical bond is characterized by a point called bonding critical point $(\mathrm{BCP})$ with a $(3,-1)$ topology between the atoms connected by a hydrogen bond. The values of electron density $[\rho(r)]$ and Laplacian of the electron density $\left(\nabla^{2} \rho(\mathrm{r})\right)$ at BCP of all dimers are summarized in Table-3.

Koch and Popelier [18] proposed three local topological properties to detect and characterize the hydrogen bond.

- Existence of BCP between proton $(\mathrm{H})$ and acceptor (Y) contact is the conformation of formation of $\mathrm{H}$-bond.

- At BCP of the H...Y the electron density $(\rho(\mathrm{r}))$ lies in the range of 0.002-0.040 a.u.

- Laplacian electronic density $\left[\nabla^{2} \rho(r)\right]$ is positive and lies in the range $0.015-0.15$ a.u.

In the present study the values of $\rho(\mathrm{r})$ and $\nabla^{2} \rho(\mathrm{r})$ varies from 0.01778 to $0.02632 \mathrm{a}$.u and 0.06355 to 0.09560 a.u. This shows that the interacting complexes have strong hydrogen bonds. From Table-3, it is observed that the large electron densities are 0.02322 a.u for COM12 and 0.02228 a.u for COM10 and 0.02215 a.u for COM8 and all Laplacian electron density values are positive indicating closed shell interactions [19]. The electron density and H-bond lengths are inversely proportional to each other so, complex COM12 posses a large electron density 0.02322 a.u with a shortest hydrogen bond length of $1.93304 \AA$. So the observed values of and for the complexes shows that $\mathrm{O}-\mathrm{H} \cdots \mathrm{N}$ interaction representing the most strong and stable hydrogen bonded complexes.

According to virial theorem the relation between local kinetic energy $\left(\mathrm{K}_{\mathrm{BCP}}\right)$, potential energy density $\left(\mathrm{V}_{\mathrm{BCP}}\right)$ and total electronic energy density $\left(\mathrm{H}_{\mathrm{BCP}}\right)$ is

$$
\begin{gathered}
\frac{1}{2} \nabla^{2} \rho(\mathrm{r})_{\mathrm{BCP}}=2 \mathrm{~K}_{\mathrm{BCP}}+\mathrm{V}_{\mathrm{BCP}} \\
\mathrm{H}_{\mathrm{BCP}}=\mathrm{K}_{\mathrm{BCP}}+\mathrm{V}_{\mathrm{BCP}}
\end{gathered}
$$

The sign of $\mathrm{H}_{\mathrm{BCP}}$ at $\mathrm{BCP}$ is an index to determine whether the molecular interactions are electrostatic $(\mathrm{H}>0)$ or covalent $(\mathrm{H}<0)$ in nature. According to Grabowski et al. [20] Laplacian of the electron density $\nabla^{2} \rho(\mathrm{r})$ and total electronic energy density $\mathrm{H}_{\mathrm{BCP}}$ are used as criteria at $\mathrm{BCP}$ of hydrogen bond:

- For weak and medium hydrogen bonds both $\nabla^{2} \rho(\mathrm{r})$ and $\mathrm{H}_{\mathrm{BCP}}>0$.

- For strong hydrogen bonds $\nabla^{2} \rho(\mathrm{r})>0$ and $\mathrm{H}_{\mathrm{BCP}}<0$.

- For very strong hydrogen bonds both $\nabla^{2} \rho(\mathrm{r})$ and $\mathrm{H}_{\mathrm{BCP}}$ $<0$.

From Table-3 both the vales of $\nabla^{2} \rho(\mathrm{r})$ and $\mathrm{H}_{\mathrm{BCP}}$ at $\mathrm{BCP}$ indicating the interactions are weak hydrogen bonds and electrostatic nature is present in all the complexes [21].

NBO analysis: The interaction between occupied Lewis type (donor) NBO's to unoccupied non-Lewis type (acceptor) NBO's can be described as a hyper conjugative electron transfer process from the donor to acceptor orbital. The second-order perturbation stabilization energy for proton donor- acceptor interaction relevant to hydrogen bond formation in 2-chloroaniline and isomeric butanols complex from NBO analysis at B3LYP/6-311++G(d,p) level of theory and are summarized in Table-4. From Table-4 in the self-associated 2-chloroaniline complex (COM1) the major interaction is that $\mathrm{N}$ (amino group) offers its lone pair to the $\sigma(\mathrm{N}-\mathrm{H})^{*}$ antibond; this interaction stabilizes the system with energy $19.83 \mathrm{kcal} \mathrm{mol}^{-1}$.

TABLE-3

TOPOLOGICAL PARAMETERS FOR BONDS OF INTERACTING ATOMS OF DIMERS: ELECTRON DENSITY ( $\rho_{\text {BCP }}$ (a.u.)), LAPLACIAN OF ELECTRON DENSITY $\left(\nabla^{2} \rho_{\text {BCP }}\right.$ (a.u.)), ELECTRON KINETIC ENERGY DENSITY ( $\mathrm{G}_{\mathrm{BCP}}$ (a.u.)), ELECTRON POTENTIAL ENERGY

\begin{tabular}{|c|c|c|c|c|c|c|}
\hline Complex & Interactions & $\left(\rho_{\mathrm{BCP}}\right.$ (a.u.) & $\nabla^{2} \rho_{\mathrm{BCP}}$ (a.u.) & $\mathrm{V}_{\mathrm{BCP}}$ (a.u.) & $\mathrm{K}_{\mathrm{BCP}}$ (a.u.) & $\mathrm{H}_{\mathrm{BCP}}$ (a.u.) \\
\hline COM1 & $\mathrm{N} 2-\mathrm{H} 11 \cdots \mathrm{N} 1$ & 0.01901 & 0.06912 & -0.013281 & 0.015301 & 0.00202 \\
\hline COM2 & $\mathrm{O} 2-\mathrm{H} 20 \cdots \mathrm{O} 1$ & 0.02632 & 0.09560 & -0.020134 & 0.022018 & 0.00188 \\
\hline COM3 & $\mathrm{O} 2-\mathrm{H} 20 \cdots \mathrm{O} 1$ & 0.02469 & 0.09492 & -0.018958 & 0.021345 & 0.00238 \\
\hline COM4 & $\mathrm{O} 2-\mathrm{H} 20 \cdots \mathrm{O} 1$ & 0.02587 & 0.09236 & -0.019543 & 0.021318 & 0.00177 \\
\hline COM5 & $\mathrm{O} 1-\mathrm{H} 1 \cdots \mathrm{O} 2$ & 0.02520 & 0.09000 & -0.018783 & 0.020642 & 0.00185 \\
\hline COM6 & $\mathrm{O} 1-\mathrm{H} 16 \cdots \mathrm{N} 1$ & 0.01978 & 0.06925 & -0.013277 & 0.015295 & 0.00201 \\
\hline COM7 & $\mathrm{N} 1-\mathrm{H} 5 \cdots \mathrm{O} 1$ & 0.01422 & 0.06355 & -0.012567 & 0.014228 & 0.00166 \\
\hline COM8 & $\mathrm{O} 1-\mathrm{H} 16 \cdots \mathrm{N} 1$ & 0.02215 & 0.66648 & -0.013662 & 0.015162 & 0.00150 \\
\hline COM9 & $\mathrm{N} 1-\mathrm{H} 5 \cdots \mathrm{O} 1$ & 0.01782 & 0.06442 & -0.011768 & 0.013937 & 0.00216 \\
\hline COM10 & $\mathrm{O} 1-\mathrm{H} 16 \cdots \mathrm{N} 1$ & 0.02228 & 0.06739 & -0.013792 & 0.015320 & 0.00152 \\
\hline COM11 & $\mathrm{N} 1-\mathrm{H} 6 \cdots \mathrm{O} 1$ & 0.01997 & 0.07367 & -0.013739 & 0.016080 & 0.00234 \\
\hline COM12 & $\mathrm{O} 1-\mathrm{H} 16 \cdots \mathrm{N} 1$ & 0.02322 & 0.06969 & -0.014594 & 0.016009 & 0.00141 \\
\hline COM13 & $\mathrm{N} 1-\mathrm{H} 5 \cdots \mathrm{O} 1$ & 0.01778 & 0.06435 & -0.011790 & 0.013939 & 0.00214 \\
\hline
\end{tabular}
$\operatorname{DENSITY}\left(\mathrm{V}_{\mathrm{BCP}}\right.$ (a.u.)), TOTAL ELECTRON ENERGY DENSITY $\left(\mathrm{H}_{\mathrm{BCP}}\right.$ (a.u.)) AT BOND CRITICAL POINT (BCP) 
TABLE-4

SECOND ORDER PERTURBATION THEORY ANALYSIS OF THE FOCK MATRIX IN THE NBO BASIS FOR THE INTERMOLECULAR INTERACTIONS FOR DIMERS

\begin{tabular}{lllc}
\hline \multicolumn{1}{c}{ Complex } & Donor NBO(i) & Acceptor NBO(j) & E(2) $(\mathrm{kJ} / \mathrm{mol})$ \\
\hline COM1 & LP(1) N1 & BD*(1)N2-H10 & 19.83 \\
COM2 & LP(1) O1 & BD*(1)O2-H11 & 8.49 \\
& LP (2) O1 & BD*(1)O2-H11 & 30.75 \\
COM3 & LP(1) O1 & BD*(1)O2-H11 & 20.45 \\
& LP (2) O1 & BD*(1)O2-H11 & 12.46 \\
COM4 & LP(1) O1 & BD*(1)O2-H11 & 6.06 \\
& LP (2) O1 & BD*(1)O2-H11 & 29.87 \\
COM5 & LP(1) O1 & BD*(1) N-H1 & 8.07 \\
& LP(2) O1 & BD*(1) N1-H1 & 26.17 \\
COM6 & LP(1) N1 & BD*(1) H16-O1 & 28.07 \\
COM7 & LP(1) O1 & BD*(1) N1-H5 & 13.46 \\
& LP(2) O1 & BD*(1) N1-H5 & 3.52 \\
COM8 & LP(1) N1 & BD*(1) H10-O1 & 32.45 \\
COM9 & LP(1) O1 & BD*(1) N1-H6 & 12.53 \\
& LP(2) O1 & BD*(1) N1-H6 & 2.81 \\
COM10 & LP(1) N1 & BD*(1) H10-O1 & 33.33 \\
COM11 & LP(1) O1 & BD*(1) N1-H6 & 13.97 \\
& LP(2) O1 & BD*(1) N1-H6 & 3.59 \\
COM12 & LP(1) N1 & BD*(1) H16-O1 & 38.52 \\
COM13 & LP(1) O1 & BD*(1) N1-H5 & 14.82 \\
& LP(2) O1 & BD*(1) N1-H5 & 2.82 \\
\hline
\end{tabular}

Whereas in isomeric butanols complexes (COM2COM5) the major interaction are the oxygen atom offers their p electrons to the $\sigma(\mathrm{O}-\mathrm{H})^{*}$ and these interaction stabilizes the systems with energies lies between $6.06-30.75 \mathrm{kcal} \mathrm{mol}^{-1}$. The orbital interactions $\mathrm{LP}(\mathrm{O}) \rightarrow \sigma(\mathrm{N}-\mathrm{H})^{*}, \mathrm{LP}(\mathrm{N}) \rightarrow \sigma(\mathrm{O}-\mathrm{H})^{*}$ in 2-chloroaniline and 1-butanol complexes (COM6-COM7) have second-order perturbation stabilization energy $\mathrm{E}$ (2) range of 13.46-28.07 kcal mol${ }^{-1}$. Whereas the orbital interactions $\mathrm{LP}(\mathrm{O}) \rightarrow \sigma(\mathrm{N}-\mathrm{H})^{*}, \mathrm{LP}(\mathrm{N}) \rightarrow \sigma(\mathrm{O}-\mathrm{H})^{*}$ in 2-chloroaniline and 2-butanol complexes (COM8-COM9) having stabilization energy $\mathrm{E}$ (2) in range of $12.53-32.45 \mathrm{kcal} \mathrm{mol}^{-1}$. The orbital interactions $\mathrm{LP}(\mathrm{O} 1) \rightarrow \sigma(\mathrm{N} 1-\mathrm{H} 5)^{*}, \mathrm{LP}(\mathrm{N} 1) \rightarrow \sigma(\mathrm{O} 1-\mathrm{H} 15)^{*}$ in 2-chloroaniline and 2-methyl-1-propanol complexes (COM10 - COM11) have second-order perturbation stabilization energies $\mathrm{E}(2)$ are $13.97-33.33 \mathrm{kcal} \mathrm{mol}^{-1}$. Finally in 2chloroaniline and 2-methyl-1-propanol complexes (COM12 - COM13) the perturbation stabilization energies E (2) are $14.82-38.52 \mathrm{kcal} \mathrm{mol}^{-1}$.

Among the thirteen hydrogen bonded dimers 2-chloroaniline and 2-methyl-2-propanol dimers exhibit strongest interaction between lone pair electrons of the proton acceptor $\mathrm{n}(\mathrm{O} 1)$ and anti-bonding orbital's of the proton donor $\sigma^{*}(\mathrm{~N} 1-$ $\mathrm{H} 5)$ of correspond to stabilization energy $38.52 \mathrm{kcal} \mathrm{mol}^{-1}$.

Non-covalent index (NCI) index: Further, to analyze the strength of hydrogen bond interaction between selected dimers (COM12, COM10 and COM8) it is useful to introduce noncovalent index (NCI index).

The NCI index method uses the reduced density gradient (RDG) [22], S(r) defined as:

$$
S(r)=\frac{|\nabla \rho(r)|}{2(3 \pi)^{1 / 3} \rho(r)^{4 / 3}}
$$

If weak intermolecular interaction is present, characteristic spikes are observed on reduced density gradient $[\mathrm{S}(\mathrm{r})]$ versus $\operatorname{sign}\left(\lambda_{2}\right) \rho$ in the low-density region of component molecules. The RDG curves for three associations $(\mathrm{O}-\mathrm{H} \cdots \mathrm{N})$ with sharp characteristic spikes are shown in Fig. 2 with isosurfaces $\mathrm{s}=0.50$. The characteristic spikes at negative indicating the presence of non-covalent interactions, whereas peaks at positive indicating repulsive and the peaks nearer to zero indicating vander Waals interaction.

Form Fig. 2, the heterodimer of 2-chloroaniline (2CA) and 1-butanol (1BA) (COM6) is connected via $\mathrm{O}-\mathrm{H} \cdots \mathrm{N}$ hydrogen bond with two low-reduced gradient spikes are at low density lies at -0.0302005and -0.0141831 a.u. In COM6 characteristic spikes very near zero, indicating weak hydrogen bond interaction. Fig. 2 shows the hetrodimer of 2-chloroaniline and 2-butanol (2BA) (COM8) low-reduced gradient spike is at low density lies at -0.039063568 a.u. Fig. 2 shows the dimer COM10 of 2-chloroaniline and 2-methyl-1-propanol (2M1P) is connected via $\mathrm{O}-\mathrm{H} \cdots \mathrm{N}$ (blue region) hydrogen bond with two low-reduced gradient spikes are at low density lies at -0.040111 and -0.0150262 a.u. Finally for the complex COM12 of 2-chloroaniline and 2-methyl-2-propanol (2M2P) low-reduced gradient spike is at low density lies at -0.0409546 a.u are shown in Fig. 2. So the stability of hydrogen bonds in cross-associated complexes follows the order as COM12 > COM10 > COM8 > COM6, which in agreement with the QTAIM analysis.

\section{Conclusion}

The intermolecular interactions between the self and crossassociated structures of 2-chloroanilie-isomeric butanols complexes have been analyzed by density functional method (DFT) at B3LYP/6-311++G (d, p) level theory. The study of optimized geometries, interaction energies, quantum theory of atom in molecule (QTAIM) and natural bonding (NBO) theory reveals that, among all the thirteen self and cross associated dimers COM12 (2-chloroaniline-2-methyl-1propanol) with $\mathrm{O}-\mathrm{H} \cdots \mathrm{N}$ hydrogen is found to be the most stable complex.

\section{ACKNOWLEDGEMENTS}

The authors are thankful to Department of Physics, Wollega University, Nekemte, Ethiopia for providing the research facilities. The authors are also very thankful to C-DAC, Pune, India for providing the computational work.

\section{CONFLICT OF INTEREST}

The authors declare that there is no conflict of interests regarding the publication of this article.

\section{REFERENCES}

1. Y. Liu, W. Liu, H. Li, Y. Yang and S. Cheng, J. Mol. Struct. THEOCHEM, 778, 49 (2006);

https://doi.org/10.1016/j.theochem.2006.07.023.

2. Z. Huang, L. Yu, Y. Dai and H. Wang, Struct. Chem., 22, 57 (2011); https://doi.org/10.1007/s11224-010-9689-4.

3. V. Umadevi, L. Senthilkumar and P. Kolandaivel, Mol. Simul., 39, 908 (2013);

https://doi.org/10.1080/08927022.2013.777840.

4. A.M. Priya, L. Senthilkumar and P. Kolandaivel, Struct. Chem., 25, 139 (2014); https://doi.org/10.1007/s11224-013-0260-y. 

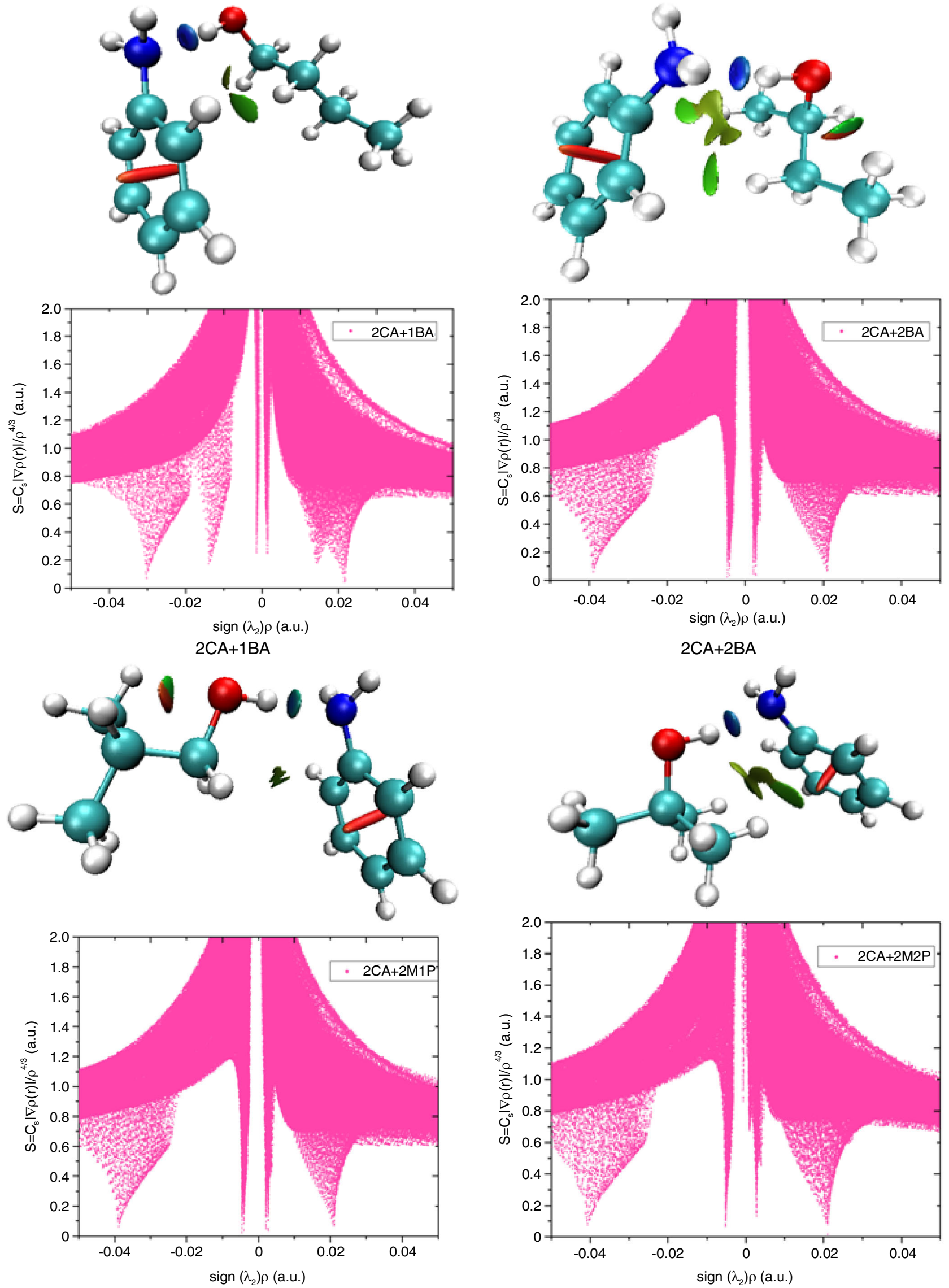

2CA+2M1P

$2 \mathrm{CA}+2 \mathrm{M} 2 \mathrm{P}$

Fig. 2. Plots of reduced density gradient versus electron density multiplied by the sign of second hessian eigen values and gradient isosurfaces with $\mathrm{s}=0.5$ a.u. for hydrogen bond association of 2-chloroaniline + isomeric butanols. The surfaces are colored on a blue-green-red scale according to values of $\operatorname{sign}\left(\lambda_{2}\right) \rho$ ranging from -0.03 to 0.02 a.u. 
5. S. Ranjbar, A. Soltanabadi and Z. Fakhri, J. Chem. Eng. Data, 61, 3077 (2016); https://doi.org/10.1021/acs.jced.6b00158.

6. M.C. Sekhar, A. Venkatesulu, T. Mohan and M. Gowrisankar, Orient. J. Chem., 31, 897 (2015); https://doi.org/10.13005/ojc/310233.

7. K. Muller-Dethlefs and P. Hobza, Chem. Rev., 100, 143 (2000); https://doi.org/10.1021/cr9900331.

8. J.M. Lehn, Chem. Int. Ed. Engl, 29, 1304 (1990); https://doi.org/10.1002/anie.199013041.

9. P. Hobza and J. Sponer, J. Chem. Rev, 99, 3247 (1999); https://doi.org/10.1021/cr9800255.

10. S. Aloisio and J.S. Francisco, Acc. Chem. Res., 33, 825 (2000); https://doi.org/10.1021/ar000097u.

11. M.C. Sekhar, T.M. Mohan and T.V. Krishna, J. Mol. Liq., 200, 263 (2014); https://doi.org/10.1016/j.molliq.2014.10.031.

12. T. Lu, Multiwfn Program, Version 2.3; http://multiwfn.codeplex.com.

13. M. Karthika, L. Senthilkumar and R. Kanakaraju, Struct. Chem., 25, 197 (2014); https://doi.org/10.1007/s11224-013-0239-8.

14. A.J.L. Jesus, M.T.S. Rosado, I. Reva, R. Fausto, M.E.S. Eusébio and J.S. Redinha, J. Phys. Chem. A, 112, 4669 (2008); https://doi.org/10.1021/jp7116196.
15. R.F. Bader and H. Essén, J. Chem. Phys., 80, 1943 (1984); https://doi.org/10.1063/1.446956.

16. A. Bondi, J. Phys. Chem., 68, 441 (1964); https://doi.org/10.1021/j100785a001.

17. M.C. Sekhar, A. Venkatesulu, M. Gowrisankar and T.S. Krishna, Phys. Chem. Liq., 55, 196 (2017); https://doi.org/10.1080/00319104.2016.1183201.

18. U. Koch and P.L.A. Popelier, Phys. Chem, 99, 9747 (1995); https://doi.org/10.1021/j100024a016.

19. P. Politzer, J.S. Murray and T. Clark, Phys. Chem. Chem. Phys., 12, 7748 (2010); https://doi.org/10.1039/c004189k.

20. S.J. Grabowski, W.A. Sokalski and J. Leszczynski, J. Phys. Chem. A, 108, 5823 (2004); https://doi.org/10.1021/jp0498740.

21. D. Cremer and E. Kraka, Chem. Int. Engl. Ed., 23, 627 (1984); https://doi.org/10.1002/anie.198406271.

22. E.R. Johnson, S. Keinan, P. Mori-Sánchez, J. Contreras-García, A.J. Cohen and W. Yang, J. Am. Chem. Soc., 132, 6498 (2010); https://doi.org/10.1021/ja100936w. 